\title{
Vitamin B12 Deficiency in Pregnancy and Lactation: Is there a Need for Pre and Post-natal Supplementation?
}

Towfida J Siddiqua ${ }^{1}$, Lindsay H Allen ${ }^{2,3}$, Rubhana Raqib ${ }^{1}$ and Tahmeed Ahmed ${ }^{1}$

${ }^{1}$ International Centre for Diarrheal Disease Research, Bangladesh

${ }^{2}$ USDA, ARS Western Human Nutrition Research Center, Davis, CA, USA

${ }^{3}$ Department of Nutrition, University of California, Davis, CA, USA

*Corresponding author: Tahmeed Ahmed, Director and Senior Scientist, Centre for Nutrition and Food Security, icddr,b 68 Shaheed Tajuddin Ahmed Sarani Mohakhali, Dhaka-1212, Bangladesh, Tel: +880-2-9827103; Fax: +880-2-9827101; E-mail: tahmeed@icddrb.org

Rec date: May 20, 2014, Acc date: Sep 02, 2014, Pub date: Sep 04, 2014

Copyright: (C) 2014 Siddiqua TJ, et al. This is an open-access article distributed under the terms of the Creative Commons Attribution License, which permits unrestricted use, distribution, and reproduction in any medium, provided the original author and source are credited

\begin{abstract}
This article reviews vitamin B12 (B12) status and deficiency during pregnancy and lactation, its effect on pregnancy, and the health of the offspring, with the aim to underscore the need for a sustainable strategy to improve maternal and infant vitamin B12 status of low and middle income countries. Vitamin B12 is a basic nutrient required for maintenance of normal erythropoiesis, cell reproduction, nucleoprotein and myelin synthesis. B12 deficiency is associated with adverse pregnancy outcomes and neurodevelopmental morbidity during infancy. Very few studies have indicated that B12 deficiency may contribute to altered immune responses in animals and humans. Additionally, no studies have shown modulation of infant motor development in response to maternal B12 supplementation. Despite the high global prevalence of B12 deficiency and its serious effects on pregnant women and offspring, there is still no consensus on the cut-off of biochemical markers (indicator of B12 deficiency) to correctly diagnose B12 deficiency in mother-infant dyad. Also, the optimum dose of B12 to normalize B12 status of mother-infant pairs in a deficient population is not known yet. In addition, markers of other functions such as neurodevelopment, immune response that may be affected by vitamin B12 deficiency should be measured to determine if they respond to supplementation. Thus, there is an urgent need to conduct more trials to find out the optimum dose, to investigate whether intervention with such pre-and post natal vitamin B12 supplementation would improve maternal, neonatal and child health outcomes in population at risk, giving emphasis on neurological processes, immune functions and epigenetic modifications. Other strategies including food based approach also require evidence based results which will help to understand effectiveness of a targeted and well-designed intervention among this population.
\end{abstract}

Keywords: Vitamin B12; Pregnancy; Lactation; Infancy

\section{Introduction}

Vitamin B12 (Cyanocobalamin), a water-soluble vitamin is an essential nutrient required for maintenance of normal erytrhropoiesis, nucleoprotein and myelin synthesis, cell reproduction and normal growth. Vitamin B12 is a necessary cofactor in the methionine synthase reaction, which converts homocysteine into methionine. Deficiency of vitamin B12 could elevate plasma homocysteine which is a risk factor for cardiovascular diseases. Methionine is the required precursor for the formation of S-adenosylmethionine, a universal methyl donor essential for methylation of phospholipids, neurotransmitters, amines, DNA, RNA and myelin basic protein. A reduction in this important methyl donor causes impaired DNA methylation that may contribute to altered fetal metabolic programming and increased risk for chronic diseases later in life. In the mitochondria vitamin $\mathrm{B} 12$ is required as a cofactor for the conversion of methylmalonyl-CoA to succinyl-CoA by the enzyme methylmalonyl-CoA mutase. In B12 deficiency, the concentration of methylmalonyl $\mathrm{CoA}$ is elevated and forms the by-product methylmalonic acid (MMA). Thus vitamin B12 insufficiency may influence carbohydrate and lipid metabolic pathways [1].

Emerging data suggest that deficiency of vitamin B12 [higher plasma B12 and holotranscobalamin (holoTC); lower plasma methylmalonic acid (MMA) and total homocysteine (tHcy) concentrations] is highly prevalent in pregnant and breastfeeding women and their infant. Impaired vitamin B12 status during pregnancy is associated with increased risk of birth defects and common complications [e.g. intrauterine growth restriction, preterm delivery, neural tube defects (NTD)] [2], and possibly immune function impairment $[3,4]$. Most of the case studies indicate that maternal depletion of the vitamin is the predominant reason for deficiency in the infant [5]. Vitamin B12 deficiency in early life may result in short- and long-term effects on infants' neurological and cognitive functions which will have profound effects on health, development and achievement of full human capacity of an entire generation of children. Maternal supplementation with B12 from early pregnancy through lactation might be an effective approach to improve both maternal and infant status, by increasing stores in utero and concentrations in breast milk. This review summarizes literature relating to B12 status and deficiency during pregnancy and lactation, its effect on pregnancy, and the health of the offspring, with the aim to underscore the need for a sustainable strategy to improve maternal and infant vitamin B12 status of low and middle income countries.

\section{Methods and Materials}

A comprehensive literature review was performed to identify articles describing the association of vitamin B12 deficiency with 
adverse pregnancy outcomes and interventions with B12 during pregnancy and infancy. Databases searched included PubMed and Google Scholar. Initial key words for the searches included "vitamin B12", "pregnancy", "lactation", "fetus or neonate", "infant" and "supplementation or intervention". Outcome measures searched included hematology, birthweight, growth, fetal growth retardation, immune response, DNA methylation and neurodevelopment. These terms were also used to undertake searches using the term "cobalamin". Further studies were identified by searching for additional terms based on results obtained from the initial searches in PubMed. Articles reporting on non- pregnant women, elderly populations and not reporting outcome of interest were screened out. Based on titles and abstract over 2000 articles were identified.

Presented here is the brief discussion on homeostasis and requirements of vitamin B12 during pregnancy and lactation. This is followed by a discussion on deficiency of vitamin B12, its adverse pregnancy outcomes and currently available studies on intervention with vitamin B12 during pregnancy and infancy.

\section{Results}

\section{Vitamin B12 homeostasis and requirements during pregnancy and lactation}

The demand for vitamin B12 increases during pregnancy due to rapid cell multiplication resulting from the uterine enlargement, placental development, and fetal growth [6]. Animal and human studies suggest that absorption the vitamin may become more efficient during pregnancy $[7,8]$. The number of receptors is usually the rate limiting factor determining the amount of $\mathrm{B} 12$ absorbed via the ileal receptors. Placental lactogen acts as a regulator of increased Intrinsic Factor (IF)-mediated vitamin B12 binding to ileal binding sites by recruiting already existing cryptic receptor rather than stimulating the synthesis of new one [9]. However despite the increased efficiency of absorption total plasma B12 declines steadily throughout pregnancy commencing with the first trimester [10]. This gradual, physiologically normal decline in the plasma B12 is thought to be due to several factors such as hemodilution, hormone fluctuations, impaired renal function, or altered concentration of binding proteins (transcobalamin and haptocorrin) [11]. The lowest concentration is observed during third trimester and it returns to prepregnancy levels within a few weeks postpartum. Vitamin B12 is actively transported to the fetus, which has a significant influence for the progressive decline of maternal vitamin B12 levels during pregnancy. Fetal demand for the vitamin has been estimated to approximately $0.3 \mu \mathrm{g} /$ day. Earlier studies by Luhby et al. showed that newly absorbed maternal B12 is more readily transported to placenta than maternal liver stores [12]. The fetal liver store of vitamin B12 is only $30 \%$ of the adult liver B12 content. Available evidence suggests that the fetus retains most of the plasma B12 to utilize for cellular reactions. The well-nourished human adult has about $2-5 \mathrm{mg}$ of the vitamin, the majority being stored in the liver which is adequate without repletion for 3-5 years. A healthy prepregnancy body stores of B12 are, therefore, sufficient to meet increased demand during pregnancy [13].

Vitamin B12 secretion into breast milk is highly dependent on current maternal intake and absorption $[14,15]$. Human milk may contain 100-fold more haptocorrin (a vitamin B12-binding protein) than serum, mostly in its free form [16]. Due to higher haptocorrin, the B12-binding capacity of milk is 1000 times greater than plasma. Almost all B12 in breast milk is bound to haptocorrin that is stable to proteolytic enzymes in the gastrointestinal tract. The function of high amounts of breast milk haptocorrin is unknown. A few studies proposed that the excess haptocorrin may play a host-defense function against pathogens in the gastrointestinal tract of breastfed infants $[17,18]$. However, this hypothesis was not supported by a systematic study on a panel of 34 commensal and pathogenic bacteria of infants [19]. There are few reports describing longitudinal changes in the concentration of breast milk vitamin B12. Samson et al. reported that the mean vitamin B12 binding capacity of colostrum is three times higher than that of mature milk [20]. Breast milk B12 concentrations decline from the high levels in colostrum to lower levels in mature milk [21].Based on the amount estimated to maintain normal serum B12 concentrations and normal hematological status in half of the adult population, the estimated average requirement for adults (EAR) is set at $2.2 \mu \mathrm{g} /$ day. The recommended dietary allowance (RDA) is 2.4 $\mu \mathrm{g} /$ day (an amount adequate to meet the requirements of $97.5 \%$ of healthy individuals). The rate of fetal accumulation ( 0.1 to $0.2 \mu \mathrm{g} / \mathrm{day}$ throughout gestation) coupled with the increased efficiency of maternal absorption increases the EAR of vitamin B12 for pregnancy by $0.2 \mu \mathrm{g} / \mathrm{day}$, with no distinction made for age of the mother. Therefore, the RDA is increased to $2.6 \mu \mathrm{g} / \mathrm{d}$ in pregnancy to support daily transfer to the fetus [22]. The Adequate Intake (AI) for infants (0 to $6 \mathrm{mo}$ ) is set at $0.4 \mu \mathrm{g} /$ day. During the first 6 months of lactation, based on the few available data the average amount of B12 secreted in the milk of mothers with adequate B12 status is approximately $0.33 \mu \mathrm{g} /$ day. To estimate the EAR for lactation, $0.33 \mu \mathrm{g} /$ day of B12 is added to the EAR of $2 \mu \mathrm{g} /$ day for adolescent girls and adult women; the result is rounded up to $+2.4 \mu \mathrm{g} /$ day. Because information is not available on the standard deviation of the requirement for B12, the RDA is set at 120 percent of the EAR. Thus the RDA for lactating women is $2.8 \mu \mathrm{g} /$ day to replace secretion of the vitamin in breast milk [6].

\section{Vitamin B12 deficiency}

The first sign of vitamin B12 deficiency is characterized by a decrease in serum holoTC, after which both serum MMA and plasma tHcy start to increase, and finally there is a reduction in serum vitamin B12. The next stages of negative B12 balance is impaired erythropoiesis, accompanied by yet lower concentrations of holoTC and serum B12, and hypersegmented neutrophils. In the end hemoglobin concentrations are reduced which results in a macrocytic anemia [23]. The most severe form of manifestation of deficiency is sub-acute combined degeneration of the spinal cord, characterized by degeneration of the posterior and lateral columns of the cord [24].

Measurement of the total vitamin B12 concentration in plasma is the usual method for assessing vitamin B12 deficiency, despite limited specificity and controversy about sensitivity [25]. However, the plasma vitamin B12 concentration is not a reliable indicator of vitamin B12 status in pregnancy. Elevated MMA and tHcy are generally considered more sensitive for diagnosing deficiency than serum B12. However, MMA is affected by intestinal bacterial overgrowth and tHcy is elevated by deficiencies of vitamin B6, folate, and riboflavin. Recent investigations show that holoTC (the metabolically active fraction of B12 available to cells) is a more sensitive indicator of vitamin B12 status than the total serum vitamin B12 level or the serum concentration of MMA and plasma tHcys [26-30]. The reference values for non-pregnant women are often applied to assess B12 deficiency in pregnant women. Since the concentrations of vitamin B12, tHcy and MMA are known to decrease during the normal course of pregnancy, low concentrations of B12 and its metabolites later in pregnancy must be interpreted with caution. Recently Fedosov 
proposed a new B12 status parameter (w) that combines all four of these biomarkers in a mathematical model [31]. Evidence is accumulating that this model is useful to make diagnosis of B12related disorders unambiguous.

Dietary deficiency of vitamin B12 is a major problem in the Indian sub-continent, Africa, Central and South America and Mexico, where it is prevalent across the life span [32,33]. Emerging data suggest that deficiency of vitamin B12 (indicated by serum or plasma B12 <150 $\mathrm{pmol} / \mathrm{L}$ ) is highly prevalent in women of reproductive age, particularly amongst populations with limited intake of animal source foods. In addition to increased requirement during pregnancy and lactation, insufficient consumption of animal-source foods, malabsorption associated with gastric diseases and nonspecific gastritis further contribute to B12 deficiency [34]. It is difficult to quantify the prevalence of deficiency in pregnant women partly due to the gradual decline in the plasma B12 concentration throughout gestation. Based on gestational week prevalence of deficiency worldwide may vary from $5 \%$ ( $<28$ days gestation) to $72 \%$ (immediately prior to delivery) $[35,36]$. In south Asia, examples of reported prevalence of deficiency include $27 \%$ of pregnant woman at early to late pregnancy (i.e. gestational week, GW $10.2 \pm 4.1$ to $32.6 \pm 3.9$ ) in rural Nepal, $74 \%$ in Haryana, $65 \%$ at GW $18-28$ in Pune and $51 \%$ at GW $\leq 14$ in urban south India [37-40]. The MINIMat study in Matlab, a rural area in Bangladesh showed that B12 deficiency was $46 \%$ in pregnant women at third trimester [41]. The JiVitA study in rural north-western Bangladesh found a prevalence of $20 \%$ deficiency $(<150 \mathrm{pmol} / \mathrm{L})$ in early pregnancy [42].The newborns and infants of vitamin B12deficient mothers have low B12 stores at birth which is further aggravated by very low availability of B12 in breast milk hindering their growth and development [43]. Maternal status of the vitamin prior to and during pregnancy, stores at birth and the concentration in breast milk all have an impact on infant B12 status [44,45]. This is substantiated by a study on maternal-newborn paired plasma samples $(n=173)$ in Norway which shows that infants born to healthy, nonvegetarian mothers and particularly those who were breastfed, had poor B12 status. Importantly, all three markers of maternal impaired B12 status predicted low serum B12, high plasma MMA, and high plasma tHcy in the newborns [46].

\section{Adverse pregnancy outcomes}

Vitamin B12 plays a key role in normal functioning of brain and nervous system [47]. Throughout the lifecycle the most serious consequence of B12 deficiency is impaired development and function of neurological processes. The underlying mechanism may involve impaired myelination or demyelination; altered $S$ adenosylmethionine: S-adenosylhomocysteine ratio; imbalance of Tumor Nacrosis Factor-alpha (TNF-alpha) and Epidermal Growth Factor (EGF) levels; and accumulated lactate in brain cells [48]. A study in Brazil showed that the S-adenosyl methionine (SAM): S adenosyl homocysteine (SAH) ratio was significantly decreased in both B12-deficient pregnant women (GW: 37-42 wk) and their newborns. Lower maternal vitamin B12 concentrations (Geometric mean: $130 \mathrm{pmol} / \mathrm{L}$ ) were associated with higher tHcy and lower SAM:SAH in newborns suggesting that methylation could be impaired in mother-infant pairs [49]. Schorah et al. found an association between low maternal plasma vitamin B12 and pregnancies affected by anencephaly [50]. Several studies reported that low maternal serum vitamin $\mathrm{B} 12$ is an independent risk factor for neural tube defects (NTDs) [51,52]. Reduced B12 binding by TC-II or holoTC also increases the risk of NTDs [53]. Nine years post-folic acid fortification, a population based case-control study in Ontario, Canada reported almost a tripling in the risk for NTDs in the presence of low maternal B12 status, measured by serum holoTC [35]. A multicenter casecontrol study in India ( $\mathrm{n}=318$ cases and $\mathrm{n}=702$ controls) demonstrated that mothers of NTD fetuses had higher plasma tHcy and lower holoTC concentrations and that a polymorphism in transcobalamin $(\mathrm{TCN} 2,776 \mathrm{C}>\mathrm{G})$ genes was a strong predictor of NTD. This study suggests a potential role of poor B12 status of Indian women in the etiology of NTD [54]. In general deficiency of vitamin B12 has been linked to a variety of abnormal neurological symptoms including: hypotonic muscles, failure to thrive, cerebral atrophy and developmental regression [48]. Maternal plasma B12 in pregnancy is also predictive of offspring cognitive performance at 9 years [55]. Children of mothers with low plasma B12 (lowest decile, $<77$ pmol/L) during pregnancy performed less well on tests of sustained attention and short-term memory compared to the children of mothers with higher plasma vitamin B12 (highest decile, $>224 \mathrm{pmol} / \mathrm{L}$ ). In rural Kenyan women $(\mathrm{n}=138), \mathrm{B} 12$ intake during pregnancy was correlated with improved scores on the infant's Brazelton Neonatal Behavioral Assessment reflex subscale score $(\mathrm{R}=-0.19, \mathrm{p}=0.05$; with adjustment for gestational age) within 3 days after birth [56]. An observational study in North Indian children $(12-18 \mathrm{mo})$ demonstrated positive associations between infants' mental development index score and vitamin B12 status [57].

A number of studies have reported an association of vitamin B12 deficiency with infertility, IUGR, preeclampsia and early pregnancy loss [58-63]. One study in Chinese women found that inadequate preconception vitamin $\mathrm{B} 12(<258 \mathrm{pmol} / \mathrm{L})$ was associated with a $60 \%$ increased risk of preterm delivery [64]. A cohort study in Bangalore, India, $(n=486)$ showed that women in the lowest tertile of serum vitamin B12 concentration during each of the three trimesters of pregnancy had a significantly higher risk of IUGR [65]. A similar study carried out in South India $(n=1838)$ observed that high folate and low vitamin $\mathrm{B} 12$ intakes $(1.2 \mu \mathrm{g} / \mathrm{d})$ during pregnancy are associated with small-for-gestational age infants [66]. Although there is little information linking vitamin B12 status with gestational diabetes, an observational cohort study ( $\mathrm{n}=785$ ) carried out in Mysore, India found an interesting association of B12 deficiency during pregnancy with obesity and gestational diabetes [67].

Increasing evidence suggest that folic acid supplemented pregnant women who may be in negative B12 balance, have increased risk for adverse maternal and infant outcomes (such as increased cardiometabolic disease risk). Low maternal B12 and a normal-to-high range of folate during pregnancy was associated with high insulin resistance and adiposity in the offspring at 5 years of age [39]. In rural Nepal, maternal low plasma B12 status in early pregnancy was associated with a significant elevation of HOMA-IR (Homeostatic model assessment-Insulin Resistance) in the 5 year old child [68]. These studies raised concerns that folic acid supplementation or added folate in the fortified foods may have adverse effects on women who have low vitamin B12 and high folate status during pregnancy or on the health of her offspring $[69,70]$.

DNA methylation, a well characterized epigenetic mechanism, is essential for normal development and can be directly affected by dietary methyl donors (protein, folate, choline, methionine, vitamins B6 and B12) in the one-carbon metabolic pathway [71]. Evidence is accumulating that adequate maternal -fetal vitamin B12 status during pregnancy is critical for donating methyl groups for $\mathrm{CpG}$ methylation and epigenetic regulation [72,73]. Impaired DNA methylation might 
ultimately affect infant development and predispose to higher disease risk later in life via developmental programming [74]. Also evidence from animal studies substantiates the importance of DNA methylation in influencing the phenotype of a growing fetus [75]. More recently a body of research has evolved around the imbalance in neurotrophic and neurotoxic cytokine levels as a key point in the pathogenesis of B12-deficient neuropathy [76].

Increasing evidence also suggests that vitamin $\mathrm{B} 12$ has important immunomodulatory effects on B- and T- cell function and humoral immunity [77-80]. In a study of Japanese men and women aged 36-83 $\mathrm{y}, \mathrm{B} 12$ deficient $(\mathrm{n}=11)$ and control $(\mathrm{n}=13)$ subjects were injected with methyl-B12 every other day for two weeks to examine the effect on lymphocyte subpopulations and NK cell activity. Antibody-dependent cell-mediated cytotoxicity, lectin-stimulated lymphocyte blast formation, and serum immunoglobulin concentrations were not changed by methyl-B12 treatment [80]. However, vitamin B12 deficient subjects had markedly fewer and less active immune cells which were revived by restoring B12 status. A similar study in Turkey [81] reported that in pernicious anemia, abnormalities (lower CD8+ lymphocytes; higher CD4/CD8 ratio, and depressed NK cell activity) in the immune system are restored by vitamin B12 replacement therapy. Interestingly, concentrations of immunoglobulins (IgG, IgA and IgM) and complements (C3) were also elevated after cyanocobalamin treatment. These results suggest that vitamin B12 may act as a modulatory agent for cellular immunity, especially affecting CD8+ cells and the natural killer cell system. In a controlled, prospective cohort study [82] serum antibody titers to 12 pneumococcal serotypes were measured by radioimmunoassay before and 4 weeks after vaccination in patients $(n=15)$ with low B12 serum concentrations vs. controls $(\mathrm{n}=15)$ with normal B12 concentrations. Immunocompetent elderly subjects with low B12 concentrations had impaired antibody response to pneumococcal polysaccharide vaccine compared to the patients with normal B12. In addition, vitamin B12 remained an independent predictor of antibody response (when adjusted for mean corpuscular volume and age). These data may point towards beneficial effects of vitamin B12 on the humoral immune system and possibly the development of vaccine specific immunity. However there is a scarcity of information in demonstrating the consequences of maternal B12 deficency on measures of maternal and infants' immunological function.

\section{Interventions during pregnancy and infancy}

There are not many reports on status and effects of pre- and postnatal vitamin B12 supplementation among mother-infant pair (Table 1). One of the earliest supplementation trials [7] with pregnant $(n=31)$ and non-pregnant women $(n=29)$ stratified the participants at baseline into three supplementation groups, 250, 500 and $1000 \mu \mathrm{g}$ B12/d (oral dose). Serum B12 concentrations were measured one and one-half and three hours later. None of the women in either the pregnant or non-pregnant group showed any response to the $250 \mu \mathrm{g}$ supplement. The pregnant women in the $500 \mu \mathrm{g}$ supplemented group had a $41.5 \%$ increase in serum B12 vs. a $16.6 \%$ increase in nonpregnant women. Pregnant women supplemented with $1000 \mu \mathrm{g}$ had an $88.8 \%$ increase in serum B12 while non-pregnant women had a $28.5 \%$ increase. These data suggests that both groups had a significant response to supplementation but the pregnant women showed greater vitamin B12 absorption than the non-pregnant women due to increased efficiency in absorption during pregnancy.

\begin{tabular}{|c|c|c|}
\hline Study design & Results & Conclusion and Limitation \\
\hline \multicolumn{3}{|l|}{ Hellegers A et al. [7] } \\
\hline $\begin{array}{l}\text { Pregnant }(n=31) \text { and non- } \\
\text { pregnant women }(n=29), \text { were stratified into three } \\
\text { supplementation groups, } 250,500 \text { and } 1000 \mu \mathrm{g} \mathrm{B12/d} \text { (oral } \\
\text { dose). Serum B12 concentrations were measured } 1,1.5 \\
\text { and } 3 \mathrm{~h} \text { later. Responder was defined as }>160 \mu \mathrm{g} \text { increase } \\
\text { observed in serum B12 concentration. }\end{array}$ & $\begin{array}{l}\text { None of the women in either the pregnant or non- } \\
\text { pregnant group showed any response to the } 250 \mu \mathrm{g} \\
\text { supplement. Pregnant women supplemented with } \\
1000 \mu \mathrm{g} \text { had an } 88.8 \% \text { increase in serum B12 while } \\
\text { non-pregnant women had a } 28.5 \% \text { increase. }\end{array}$ & $\begin{array}{l}\text { Compared to non -pregnant women absorption } \\
\text { of vitamin B12 is significantly increased in } \\
\text { pregnancy. } \\
\text { Serum B12 was the only response measured. }\end{array}$ \\
\hline \multicolumn{3}{|l|}{ Eneroth $\mathrm{H}$ et al. [83] } \\
\hline $\begin{array}{l}\text { RCT in Bangladesh, } n=4436 \text { ( } G W \geq 14 \text { ). Daily micronutrient } \\
\text { supplements either: } 1 \text { ) folic acid and } 30 \text { mg iron; Fe30Fol or } \\
\text { 2) folic acid and } 60 \mathrm{mg} \text { iron; or } 3 \text { ) a multiple micronutrient } \\
\text { including folic acid and } 30 \mathrm{mg} \text { iron (MMS). } \\
\text { Supplementation continued up to } 3 \mathrm{mo} \text { postpartum. }\end{array}$ & $\begin{array}{l}46 \%(n=670) \text { of women had low B12 status, At } 6 \text { mo } \\
\text { prevalence of infant B12 deficiency significantly lower } \\
\text { in the MMS group than in the Fe30Fol group ( } 26.1 \text { vs. } \\
36.5 \%) \text {. }\end{array}$ & $\begin{array}{l}\text { B12 deficiency highly prevalent in this } \\
\text { population; MMS may have a beneficial effect } \\
\text { on B12 status in infancy. } \\
\text { Small effect size; B12 was the only response } \\
\text { measured; No assay of newborn B12 status. }\end{array}$ \\
\hline \multicolumn{3}{|l|}{ Baylin A et al. [84] } \\
\hline 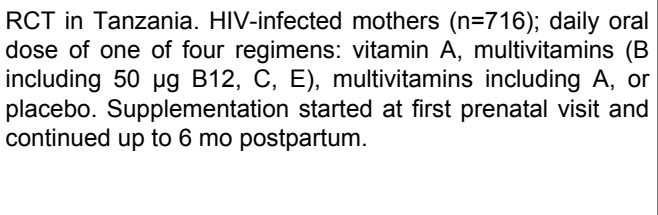 & $\begin{array}{l}\text { Compared to infants from non-multivitamin- } \\
\text { supplemented mothers, multivitamins increased } B 12 \\
\text { at } 6 \mathrm{wk} \text { and } 6 \text { mo (mean differences }=176 \text { pmol/L, and } \\
127 \mathrm{pmol} / \mathrm{L} \text {, respectively), significant reductions in the } \\
\text { prevalence of B12 deficiency at } 6 \text { mo. }\end{array}$ & $\begin{array}{l}\text { Multivitamin (B, C, E) supplementation had } \\
\text { major effect on serum B12 at } 6 \text { wk that was } \\
\text { sustained through } 6 \text { mo of age. } \\
\text { B12 was the only response measured; } \\
\text { no information on breast feeding frequency; } \\
\text { complementary feeding. }\end{array}$ \\
\hline \multicolumn{3}{|l|}{ Duggan C [85] } \\
\hline $\begin{array}{l}\text { RCT in India. Pregnant women }(<14 \mathrm{GW}) \text { randomized to } \\
\text { receive either an oral B12 }(50 \mu \mathrm{g} / \text { day }) \text { or placebo through } 6 \\
\text { wk postpartum. }\end{array}$ & $\begin{array}{l}\text { Compared to the placebo group, supplemented } \\
\text { women had higher median plasma B12 } \\
\text { concentrations at both the } 2 \text { nd ( } 216 \text { vs. } 111 \mathrm{pmol} / \mathrm{L})\end{array}$ & $\begin{array}{l}\text { Oral maternal vitamin B12 supplementation is } \\
\text { effective to improve maternal and infant B12 } \\
\text { status. }\end{array}$ \\
\hline
\end{tabular}


Citation: Siddiqua JT, Allen HL, Raqib R, Ahmed T (2014) Vitamin B12 Deficiency in Pregnancy and Lactation: Is there a Need for Pre and Postnatal Supplementation?. J Nutr Disorders Ther 4: 142. doi:10.4172/2161-0509.1000142

Page 5 of 8

\begin{tabular}{|c|c|c|}
\hline & $\begin{array}{l}\text { and 3rd ( } 184 \mathrm{vs.} 105 \mathrm{pmol} / \mathrm{L}) \text { trimesters; higher breast } \\
\text { milk B12 (136 vs. } 87 \mathrm{pmol} / \mathrm{L}) \text { in the placebo group; } \\
\text { higher infant plasma B12 (199 vs. } 136 \mathrm{pmol} / \mathrm{L}) \text {; } \\
\text { reduced infant MMA and tHcy }\end{array}$ & $\begin{array}{l}\text { HoloTC was not assayed; data were not } \\
\text { available for women after postpartum; too short } \\
\text { follow-up period for infants B12 status. }\end{array}$ \\
\hline \multicolumn{3}{|l|}{ Monsen et al. [86] } \\
\hline $\begin{array}{l}\text { RCT in Norway. } \mathrm{n}=107 \text { infants }(6 \mathrm{wk}) \text { randomized to } \\
\text { receive either an intramuscular injection of } \mathrm{B} 12(400 \mu \mathrm{g}) \text { or } \\
\text { no intervention (control). Biomarkers were assayed at } \\
\text { enrollment and at age } 4 \mathrm{mo} \text {. }\end{array}$ & $\begin{array}{l}\text { Compared to the control group supplement-treated } \\
\text { infants had } 75 \% \text { higher median serum B12, raised } \\
\text { serum B12 (IQR: } 291-497 \mathrm{pmol} / \mathrm{L} \text { ), and lowered MMA } \\
\text { (from } 0.58 \text { to } 0.20 \mu \mathrm{mol} / \mathrm{L} \text { ) and tHcy (from } 7.46 \text { to } 4.57 \\
\mu \mathrm{mol} / \mathrm{L} \text { ) at } 4 \mathrm{mo} \text {. }\end{array}$ & $\begin{array}{l}\text { Supplementation can normalize a metabolic } \\
\text { profile consistent with impaired B12 status in } \\
\text { young infants. } \\
\text { Control group did not receive placebo } \\
\text { medication; effect on neurological } \\
\text { parameters were not assessed. }\end{array}$ \\
\hline \multicolumn{3}{|l|}{ Torsvik et al. [87] } \\
\hline $\begin{array}{l}\text { RCT, infants ( } n=79,<8 \mathrm{mo} \text {, plasma tHcy concentration } \geq 6.5 \\
\mu \mathrm{mol} / \mathrm{L})) \text { randomized to either an intramuscular injection of } \\
\mathrm{B} 12(400 \mu \mathrm{g}) \text { or a sham injection }\end{array}$ & $\begin{array}{l}\text { Supplementation decreased plasma tHcy by } 54 \% \text {, and } \\
\text { MMA by } 84 \% \text {, no significant changes in the placebo } \\
\text { group. } \\
\text { Sig. higher motor function [Alberta Infants Motor Scale } \\
\text { (AIMS)] score in the B12 group than in the placebo } \\
\text { group }(7.0(5.0,9.0) \text { vs. } 4.5(3.3,6.0) \text { ]. Higher } \\
\text { proportion showed improvements in regurgitations } \\
(69 \% \text { vs. } 29 \% \text {, respectively; } P=0.003) \text {. }\end{array}$ & $\begin{array}{l}\text { In infants with impaired B12 function, } 400 \mu \mathrm{\mu g} \\
\text { intramuscular injection of B12 resulted in } \\
\text { biochemical evidence of repletion and } \\
\text { improvement in motor function and } \\
\text { regurgitations; } \\
\text { too short follow-up period (1 mo). }\end{array}$ \\
\hline
\end{tabular}

Table 1: Summary of interventions with vitamin B12 (pregnant/non-pregnant women and infants) ${ }^{1}$

Many intervention studies among mother-infant dyads have included B12 in multivitamin supplements. The MINIMAT trial in Matlab reported multiple micronutrient supplementation with the recommended dietary allowances (RDA) $(2.6 \mu \mathrm{g} / \mathrm{d}$ B12 in pregnancy up to 3 months postpartum) did not significantly impact on maternal B12 deficiency. However it only reduced infant deficiency at 6 mo to $26 \%$ [83]. In a randomized, placebo-controlled trial in Tanzania, multivitamin supplementation (with $50 \mu \mathrm{g}$ B12) of HIV-infected mothers $(n=716)$ throughout pregnancy upto 6 months postpartum significantly increased infant plasma vitamin B12 concentrations at age 6 weeks and 6 months (mean differences:176 and 127 pmol/l, respectively) and decreased the prevalence of vitamin B12 deficiency compared to the placebo [84]. However, adverse or improved outcomes cannot be attributed to any specific vitamin in such trials with multivitamin supplementation. A recent randomized study among Indian women reported that supplementation with B12 (50 $\mu \mathrm{g} /$ day) throughout pregnancy up to $6 \mathrm{wk}$ postpartum increased the concentration in maternal and infant plasma and breast milk B12 content [85]. However, both the dose and the duration of supplementation are important to sustain optimum B12 status in circulation in mother-infant pairs. The observations by Duggan et al should be replicated by well-designed RCTs with optimum dose and extended beyond their $6 \mathrm{wk}$ postpartum observation period. To investigate benefits of vitamin B12 supplementation, including effects on anemia, immune function and breast milk, we have conducted a pilot study in which Bangladeshi women ( $\mathrm{n}=68,18-35 \mathrm{y}, \mathrm{Hb}<110 \mathrm{~g} / \mathrm{L}$, 11-14 wk pregnant) were randomized to $250 \mu \mathrm{g} \mathrm{B12/day} \mathrm{or} \mathrm{a} \mathrm{placebo}$ through 3 mo postpartum. Both groups also received $400 \mu \mathrm{g}$ folic acid $+60 \mathrm{mg}$ iron daily as standard of care. A high prevalence of deficient and marginal status of B12 was reported in early pregnancy. Furthermore, maternal deficiency predicted poorer infant B12 status through 3 mo postpartum. These observations imply that it is critically important to assess the adequacy of the vitamin in maternal and infant plasma and breast milk in response to adequate pre- and post-natal doses of B12, in populations with a high prevalence of deficiency.

In a randomized study in Norway, intramuscular injection of 400 $\mu \mathrm{g}$ of vitamin $\mathrm{B} 12$ to infants $(\mathrm{n}=54)$ at 6 weeks raised serum B12 (IQR: 291-497 pmol/L), and lowered MMA (from 0.58 to 0.20 $\mu \mathrm{mol} / \mathrm{L}$ ) and tHcy (from 7.46 to $4.57 \mu \mathrm{mol} / \mathrm{L}$ ) at 4 months, compared to a group $(n=51)$ that received no intervention [86]. Despite the high prevalence of vitamin B12 deficiency amongst pregnant and breastfeeding women and their infants, there is a paucity of information on infant development in response to vitamin B12 supplementation during pregnancy or infancy. A recent double-blind, randomized controlled trial in infants $(<8$ months of age $)$ demonstrated credible evidence that intramuscular injection of $400 \mu \mathrm{g}$ hydroxycobalamin resulted in B12 repletion, improvements in motor function and reduced regurgitations linked to neuromuscular coordination [87]. This apparent beneficial effect of vitamin B12 administration during infancy and its underlying mechanism requires more advanced investigations.

\section{Discussion}

The highlights of the review are increased B12 requirements during pregnancy and lactation, adverse pregnancy outcomes and short and long term consequences of B12 deficiency on child health. The review shows that the reference range for vitamin B12 status during pregnancy/lactation and the optimum dose to rectify the deficiency are still not clear and need more research. Very few RCTs have been conducted with inconclusive data on appropriate biomarkers of B12 status and short- and long-term health outcomes.

It is well recognized that requirement for B12 increases during pregnancy and lactation. Vitamin B12 needs during pregnancy and infancy are so high that it is virtually impossible for these to be met through diet alone, especially in low and middle income countries. 
Thus, in population with high risk of B12 deficiency to reduce the gap between needs and intake, it is not imprudent to propose increased intake of B12 during pregnancy and lactation either through supplementation or via fortified food.

There have been minimal investigations into the effects of vitamin B12 supplementation during pregnancy, lactation or infancy on maternal and infants' health outcomes. Given the potential adverse effects of vitamin B12 deficiency on maternal and infant development, it is important to define B12 deficiency during each trimester using appropriate cut off. It is also important to conduct rigorously designed RCTs to find the optimum dose of B12 supplement required to replenish the deficiency, to understand factors that may explain variations in response to different doses of supplementation and impact of supplementation on metabolomic, epigenetic, immune and endocrine measures that influence the overall health outcomes in mothers and children. The long-term implication of reduced vitamin B12 status in children born to vitamin B12 deficient mothers and its underlying mechanism is not well understood and extended follow-up studies on metabolic pathways and neurodevelopment of children are required to answer these interesting questions.

Worldwide, an integrated policy has been adopted to reduce the incidence of NTD, preferably by iron-folic acid supplementation, but the high prevalence of deficiency and depletion of vitamin B12 during pregnancy and infancy leading to increase risk of neural tube defects, delayed neurological development, low birth weight and higher disease risk later in life, has received less attention by policy makers. No unified guidelines are available to assist obstetricians or pediatricians to prescribe optimum doses of vitamin B12 during pregnancy and postpartum. From a public health point of view, the identification of exact strategy to reduce vitamin B12 deficiency is of prime interest. However, defining an appropriate strategy for the prevention of deficiency critically depends on evidence based results. Most of the reported studies show high prevalence of vitamin B12 deficiency in low and middle income populations. However, there is a lack of adequately designed RCTs to evaluate the functional outcomes of B12 supplementation. Thus, in conclusion, there is an urgent need to advance our knowledge in a population specific manner to further improve the current guidelines of nutritional interventions for pregnant and lactating women that has direct relevance to child health.

\section{Acknowledgment}

This research protocol/activity/study was funded by core donors which provide unrestricted support to icddr,b for its operations and research. Current donors providing unrestricted support include: Australian Agency for International Development (AusAID), Government of the People's Republic of Bangladesh; Canadian International Development Agency (CIDA), Swedish International Development Cooperation Agency (Sida), and the Department for International Development, UK (DFID). We gratefully acknowledge these donors for their support and commitment to icddr,b's research efforts.

\section{References}

1. Rush EC, Katre P, Yajnik CS (2014) Vitamin B12: one carbon metabolism, fetal growth and programming for chronic disease. Eur J Clin Nutr 68: 2-7.

2. Refsum H (2001) Folate, vitamin B12 and homocysteine in relation to birth defects and pregnancy outcome. Br J Nutr 85 Suppl 2: S109-113.
3. Tang AM, Graham NM, Chandra RK, Saah AJ (1997) Low serum vitamin B-12 concentrations are associated with faster human immunodeficiency virus type 1 (HIV-1) disease progression. J Nutr 127: 345-351.

4. Bunout D, Barrera G, Hirsch S, Gattas V, de la Maza MP, et al. (2004) Effects of a nutritional supplement on the immune response and cytokine production in free-living Chilean elderly. JPEN J Parenter Enteral Nutr 28: 348-354.

5. Allen LH (1994) Vitamin B12 metabolism and status during pregnancy, lactation and infancy. Adv Exp Med Biol 352: 173-186.

6. In: Dietary Reference Intakes for Thiamin, Riboflavin, Niacin, Vitamin B6, Folate, Vitamin B12, Pantothenic Acid, Biotin, and Choline. (1998) The National Academies Collection: Reports funded by National Institutes of Health. Washington (DC),

7. HELLEGERS A, OKUDA K, NESBITT RE Jr, SMITH DW, CHOW BF (1957) Vitamin B12 absorption in pregnancy and in the newborn. Am J Clin Nutr 5: 327-331.

8. Brown J, Robertson J, Gallagher N (1977) Humoral regulation of vitamin B12 absorption by pregnant mouse small intestine. Gastroenterology 72: 881-888.

9. Robertson JA, Gallagher ND (1983) Increased intestinal uptake of cobalamin in pregnancy does not require synthesis of new receptors. Biochim Biophys Acta 757: 145-150.

10. Fernandes-Costa F, Metz J (1982) Levels of transcobalamins I, II, and III during pregnancy and in cord blood. Am J Clin Nutr 35: 87-94.

11. Guerra-Shinohara EM, Morita OE, Peres S, Pagliusi RA, Sampaio Neto LF, et al. (2004) Low ratio of S-adenosylmethionine to Sadenosylhomocysteine is associated with vitamin deficiency in Brazilian pregnant women and newborns. Am J Clin Nutr 80: 1312-1321.

12. Luhby AL CJ, Donnenfeld AM, Herrero JM, Teller DN, Wenig JB (1958) Observations on transfer of vitamin B12 from mother to fetus and newborn. Am J Dis Child 96:532-533

13. Dror DK, Allen LH (2012) Interventions with vitamins B6, B12 and C in pregnancy. Paediatr Perinat Epidemiol 26 Suppl 1: 55-74.

14. Allen LH (1994) Maternal micronutrient malnutrition: effects on breast milk and infant nutrition, and priorities for intervention. SCN News : 21-24.

15. Casterline JE, Allen LH, Ruel MT (1997) Vitamin B-12 deficiency is very prevalent in lactating Guatemalan women and their infants at three months postpartum. J Nutr 127: 1966-1972.

16. Lildballe DL, Hardlei TF, Allen LH, Nexo E (2009) High concentrations of haptocorrin interfere with routine measurement of cobalamins in human serum and milk. A problem and its solution. Clin Chem Lab Med 47: 182-187.

17. Gullberg R (1973) Possible influence of vitamin B12-binding protein in milk on the intestinal flora in breast-fed infants. I. B12-binding proteins in human and bovine milk. Scand J Gastroenterol 8: 497-503.

18. Ford J, Scott K, Sansom B, Taylor P (1975) Some observations on the possible nutritional significance of vitamin B12-and folate-binding proteins in milk. Absorption of [58Co]cyanocobalamin by suckling piglets. The British journal of nutrition 34:469-492

19. Greibe E, Lildballe DL, Streym S, Vestergaard P, Rejnmark L, et al. (2013) Cobalamin and haptocorrin in human milk and cobalamin-related variables in mother and child: a 9-mo longitudinal study. Am J Clin Nutr 98: 389-395.

20. Samson RR, McClelland DB (1980) Vitamin B12 in human colostrum and milk. Quantitation of the vitamin and its binder and the uptake of bound vitamin B12 by intestinal bacteria. Acta Paediatr Scand 69: 93-99.

21. Greibe E, Lildballe DL, Streym S, Vestergaard P, Rejnmark L, et al. (2013) Cobalamin and haptocorrin in human milk and cobalamin-related variables in mother and child: a 9-mo longitudinal study. Am J Clin Nutr 98: 389-395.

22. Yates AA, Schlicker SA, Suitor CW (1998) Dietary Reference Intakes: the new basis for recommendations for calcium and related nutrients, B vitamins, and choline. J Am Diet Assoc 98: 699-706. 
23. Herbert V (1994) Staging vitamin B-12 (cobalamin) status in vegetarians. Am J Clin Nutr 59: 1213S-1222S.

24. Healton EB, Savage DG, Brust JC, Garrett TJ, Lindenbaum J (1991) Neurologic aspects of cobalamin deficiency. Medicine (Baltimore) 70 229-245.

25. Green R (1995) Metabolite assays in cobalamin and folate deficiency. Baillieres Clin Haematol 8: 533-566.

26. Fedosov SN (2010) Metabolic signs of vitamin B(12) deficiency in humans: computational model and its implications for diagnostics. Metabolism 59: 1124-1138.

27. Herrmann W, Obeid R, Schorr H, Geisel J (2003) Functional vitamin B12 deficiency and determination of holotranscobalamin in populations at risk. Clin Chem Lab Med 41: 1478-1488.

28. Obeid R, Herrmann W (2007) Holotranscobalamin in laboratory diagnosis of cobalamin deficiency compared to total cobalamin and methylmalonic acid. Clin Chem Lab Med 45: 1746-1750.

29. Morkbak A, Hvas A, Milman N, Nexo E (2007) Holotranscobalamin remains unchanged during pregnancy. Longitudinal changes of cobalamins and their binding proteins during pregnancy and postpartum. Haematologica 92:1711-1712

30. Vanderjagt DJ, Ujah IA, Ikeh EI, Bryant J, Pam V, et al. (2011) Assessment of the vitamin B12 status of pregnant women in Nigeria using plasma holotranscobalamin. ISRN Obstet Gynecol 2011: 365894.

31. Fedosov SN (2013) Biochemical markers of vitamin B12 deficiency combined in one diagnostic parameter: the age-dependence and association with cognitive function and blood hemoglobin. Clin Chim Acta 422: 47-53

32. Allen LH (2004) Folate and vitamin B12 status in the Americas. Nutr Rev 62: S29-33.

33. Kraemer K ZM (2007) Nutritional Anemia. Sight and Life press, Basel

34. Allen LH (1994) Vitamin B12 metabolism and status during pregnancy, lactation and infancy. Adv Exp Med Biol 352: 173-186.

35. Ray JG, Goodman J, O'Mahoney PR, Mamdani MM, Jiang D (2008) High rate of maternal vitamin B12 deficiency nearly a decade after Canadian folic acid flour fortification. QJM 101: 475-477.

36. Koc A, Kocyigit A, Soran M, Demir N, Sevinc E, et al. (2006) High frequency of maternal vitamin B12 deficiency as an important cause of infantile vitamin B12 deficiency in Sanliurfa province of Turkey. Eur J Nutr 45: 291-297.

37. Pathak P, Kapil U, Yajnik CS, Kapoor SK, Dwivedi SN, et al. (2007) Iron, folate, and vitamin B12 stores among pregnant women in a rural area of Haryana State, India. Food Nutr Bull 28: 435-438.

38. Stewart CP CP, Schulze KJ, Arguello M, LeClerq SC, Khatry SK, West KP $\mathrm{Jr}$ (2011) Low maternal vitamin B-12 status is associated with offspring insulin resistance regardless of antenatal micronutrient supplementation in rural Nepal. The Journal of nutrition 141:1912-1917.

39. Yajnik CS, Deshpande SS, Jackson AA, Refsum H, Rao S, et al. (2008) Vitamin B12 and folate concentrations during pregnancy and insulin resistance in the offspring: the Pune Maternal Nutrition Study. Diabetologia 51: 29-38.

40. Samuel TM, Duggan C, Thomas T, Bosch R, Rajendran R, et al. (2013) Vitamin $\mathrm{B}(12)$ intake and status in early pregnancy among urban South Indian women. Ann Nutr Metab 62: 113-122.

41. Lindström E, Hossain MB, Lönnerdal B, Raqib R, El Arifeen S, et al. (2011) Prevalence of anemia and micronutrient deficiencies in early pregnancy in rural Bangladesh, the MINIMat trial. Acta Obstet Gynecol Scand 90: 47-56.

42. Shamim AA, Kabir A, Merrill RD, Ali H, Rashid M, et al. (2013) Plasma zinc, vitamin $\mathrm{B}(12)$ and $\hat{\mathrm{I}} \pm$-tocopherol are positively and plasma $\hat{\mathrm{I}}^{3}$ tocopherol is negatively associated with $\mathrm{Hb}$ concentration in early pregnancy in north-west Bangladesh. Public Health Nutr 16: 1354-1361.

43. Allen LH (2012) B vitamins in breast milk: relative importance of maternal status and intake, and effects on infant status and function. Adv Nutr 3: 362-369.
44. Allen LH (2012) B vitamins in breast milk: relative importance of maternal status and intake, and effects on infant status and function. Adv Nutr 3: 362-369.

45. Hay G, Clausen T, Whitelaw A, Trygg K, Johnston C, et al. (2010) Maternal folate and cobalamin status predicts vitamin status in newborns and 6-month-old infants. J Nutr 140: 557-564.

46. Bjørke Monsen AL, Ueland PM, Vollset SE, Guttormsen AB, Markestad T, et al. (2001) Determinants of cobalamin status in newborns. Pediatrics 108: 624-630.

47. Nyaradi A, Li J, Hickling S, Foster J, Oddy WH (2013) The role of nutrition in children's neurocognitive development, from pregnancy through childhood. Front Hum Neurosci 7: 97.

48. Dror DK, Allen LH (2008) Effect of vitamin B12 deficiency on neurodevelopment in infants: current knowledge and possible mechanisms. Nutr Rev 66: 250-255.

49. Guerra-Shinohara EM, Morita OE, Peres S, Pagliusi RA, Sampaio Neto LF, et al. (2004) Low ratio of S-adenosylmethionine to Sadenosylhomocysteine is associated with vitamin deficiency in Brazilian pregnant women and newborns. Am J Clin Nutr 80: 1312-1321.

50. Schorah CJ, Smithells RW, Scott J (1980) Vitamin B12 and anencephaly. Lancet 1: 880 .

51. Kirke PN, Molloy AM, Daly LE, Burke H, Weir DG, et al. (1993) Maternal plasma folate and vitamin B12 are independent risk factors for neural tube defects. Q J Med 86: 703-708.

52. Suarez L, Hendricks K, Felkner M, Gunter E (2003) Maternal serum B12 levels and risk for neural tube defects in a Texas-Mexico border population. Ann Epidemiol 13: 81-88.

53. Afman LA, Van Der Put NM, Thomas CM, Trijbels JM, Blom HJ (2001) Reduced vitamin B12 binding by transcobalamin II increases the risk of neural tube defects. QJM 94: 159-166.

54. Godbole K, Gayathri P, Ghule S, Sasirekha BV, Kanitkar-Damle A, et al. (2011) Maternal one-carbon metabolism, MTHFR and TCN2 genotypes and neural tube defects in India. Birth Defects Res A Clin Mol Teratol 91: 848-856.

55. Bhate V, Deshpande S, Bhat D, Joshi N, Ladkat R, et al. (2008) Vitamin B12 status of pregnant Indian women and cognitive function in their 9year-old children. Food Nutr Bull 29: 249-254.

56. Neumann C, Oace S, Chaparro M, Herman D, Drorbaugh N, Bwibo N (2013) Low vitamin B12 intake during pregnancy and lactation and low breastmilk vitamin 12 content in rural Kenyan women consuming predominantly maize diets. Food and nutrition bulletin 34:151-159

57. Strand TA, Taneja S, Ueland PM, Refsum H, Bahl R, et al. (2013) Cobalamin and folate status predicts mental development scores in North Indian children 12-18 mo of age. Am J Clin Nutr 97: 310-317.

58. Tamura T, Picciano MF (2006) Folate and human reproduction. Am J Clin Nutr 83: 993-1016.

59. Mulinare J, Erickson JD (1997) Prevention of neural tube defects. Teratology 56: 17-18.

60. van der Put NM1, Steegers-Theunissen RP, Frosst P, Trijbels FJ, Eskes TK, et al. (1995) Mutated methylenetetrahydrofolate reductase as a risk factor for spina bifida. Lancet 346: 1070-1071.

61. Bergen NE, Jaddoe VW, Timmermans S, Hofman A, Lindemans J, et al. (2012) Homocysteine and folate concentrations in early pregnancy and the risk of adverse pregnancy outcomes: the Generation R Study. BJOG 119: 739-751.

62. Refsum H (2001) Folate, vitamin B12 and homocysteine in relation to birth defects and pregnancy outcome. Br J Nutr 85 Suppl 2: S109-113.

63. Molloy AM, Kirke PN, Brody LC, Scott JM, Mills JL (2008) Effects of folate and vitamin B12 deficiencies during pregnancy on fetal, infant, and child development. Food Nutr Bull 29: S101-111.

64. Sadowitz PD, Livingston A, Cavanaugh RM (1986) Developmental regression as an early manifestation of vitamin B12 deficiency. Clin Pediatr (Phila) 25: 369-371. 
Citation: Siddiqua JT, Allen HL, Raqib R, Ahmed T (2014) Vitamin B12 Deficiency in Pregnancy and Lactation: Is there a Need for Pre and Postnatal Supplementation?. J Nutr Disorders Ther 4: 142. doi:10.4172/2161-0509.1000142

Page 8 of 8

65. Muthayya S, Kurpad AV, Duggan CP, Bosch RJ, Dwarkanath P, et al. (2006) Low maternal vitamin B12 status is associated with intrauterine growth retardation in urban South Indians. Eur J Clin Nutr 60: 791-801.

66. Dwarkanath P, Barzilay JR, Thomas T, Thomas A, Bhat S, et al. (2013) High folate and low vitamin B-12 intakes during pregnancy are associated with small-for-gestational age infants in South Indian women a prospective observational cohort study. Am J Clin Nutr 98: 1450-1458.

67. Krishnaveni GV, Hill JC, Veena SR, Bhat DS, Wills AK, et al. (2009) Low plasma vitamin B12 in pregnancy is associated with gestational 'diabesity' and later diabetes. Diabetologia 52: 2350-2358.

68. Bondevik GT, Schneede J, Refsum H, Lie RT, Ulstein M, et al. (2001) Homocysteine and methylmalonic acid levels in pregnant Nepali women. Should cobalamin supplementation be considered? Eur J Clin Nutr 55: 856-864.

69. Rosenberg IH (2008) Metabolic programming of offspring by vitamin B12/folate imbalance during pregnancy. Diabetologia 51: 6-7.

70. Lucock M, Yates Z (2009) Folic acid fortification: a double-edged sword. Curr Opin Clin Nutr Metab Care 12: 555-564.

71. Zeisel SH (2009) Importance of methyl donors during reproduction. Am J Clin Nutr 89: 673S-7S.

72. McKay JA, Groom A, Potter C, Coneyworth LJ, Ford D, et al. (2012) Genetic and non-genetic influences during pregnancy on infant global and site specific DNA methylation: role for folate gene variants and vitamin B12. PLoS One 7: e33290.

73. Ba Y, Yu H, Liu F, Geng X, Zhu C, et al. (2011) Relationship of folate, vitamin B12 and methylation of insulin-like growth factor-II in maternal and cord blood. Eur J Clin Nutr 65: 480-485.

74. Hanson MA, Low FM, Gluckman PD (2011) Epigenetic epidemiology: the rebirth of soft inheritance. Ann Nutr Metab 58 Suppl 2: 8-15.

75. Waterland RA, Jirtle RL (2003) Transposable elements: targets for early nutritional effects on epigenetic gene regulation. Mol Cell Biol 23: 5293-5300.

76. Scalabrino G (2009) The multi-faceted basis of vitamin B12 (cobalamin) neurotrophism in adult central nervous system: Lessons learned from its deficiency. Prog Neurobiol 88: 203-220.

77. Dietary Reference Intakes for Thiamin, Riboflavin, Niacin, Vitamin B6, Folate, Vitamin B12, Pantothenic Acid, Biotin, and Choline. (1998) Washington (DC)
78. Tang AM, Graham NM, Chandra RK, Saah AJ (1997) Low serum vitamin B-12 concentrations are associated with faster human immunodeficiency virus type 1 (HIV-1) disease progression. J Nutr 127: 345-351.

79. Bunout D, Barrera G, Hirsch S, Gattas V, de la Maza MP, et al. (2004) Effects of a nutritional supplement on the immune response and cytokine production in free-living Chilean elderly. JPEN J Parenter Enteral Nutr 28: 348-354.

80. Vellema P, Rutten VP, Hoek A, Moll L, Wentink GH (1996) The effect of cobalt supplementation on the immune response in vitamin B12 deficient Texel lambs. Vet Immunol Immunopathol 55: 151-161.

81. Erkurt MA, Aydogdu I, DikilitaÅŸ M, Kuku I, Kaya E, et al. (2008) Effects of cyanocobalamin on immunity in patients with pernicious anemia. Med Princ Pract 17: 131-135.

82. Fata FT, Herzlich BC, Schiffman G, Ast AL (1996) Impaired antibody responses to pneumococcal polysaccharide in elderly patients with low serum vitamin B12 levels. Ann Intern Med 124: 299-304.

83. Eneroth H EAS, Persson LA, Lönnerdal B, Hossain MB, Stephensen CB, Ekström EC (2010) Maternal Multiple Micronutrient Supplementation Has Limited Impact on Micronutrient Status of Bangladeshi Infants Compared with Standard Iron andFolic Acid Supplementation. The Journal of nutrition 140:618-624

84. Baylin A, Villamor E, Rifai N, Msamanga G, Fawzi WW (2005) Effect of vitamin supplementation to HIV-infected pregnant women on the micronutrient status of their infants. Eur J Clin Nutr 59: 960-968.

85. Duggan C, Srinivasan K, Thomas T, Samuel T, Rajendran R, et al. (2014) Vitamin B-12 supplementation during pregnancy and early lactation increases maternal, breast milk, and infant measures of vitamin B-12 status. J Nutr 144: 758-764.

86. Bjørke-Monsen AL, Torsvik I, Saetran H, Markestad T, Ueland PM (2008) Common metabolic profile in infants indicating impaired cobalamin status responds to cobalamin supplementation. Pediatrics 122: 83-91.

87. Torsvik I, Ueland PM, Markestad T, Bjørke-Monsen AL (2013) Cobalamin supplementation improves motor development and regurgitations in infants: results from a randomized intervention study. Am J Clin Nutr 98: 1233-1240. 